\title{
Utilização de óleo de soja em rações para vacas leiteiras no período de transição: consumo, produção e composição do leite
}

\author{
Anselmo Domingos Ferreira Santos ${ }^{1}$, Ciro Alexandre Alves Torres ${ }^{2}$, Francisco Palma \\ Rennó $^{3}$, Mariana Resende Soares Drumond ${ }^{4}$, José Esler de Freitas Júnior ${ }^{5}$
}

\footnotetext{
${ }^{1}$ Curso de Medicina Veterinária da Faculdade Pio Décimo, Av: Tancredo Neves, n55655, Bairro Jabotiana, Aracaju, SE, CEP: 49095-000

2 Departamento de Zootecnia da Universidade Federal de Viçosa, Campus Universitário, Viçosa, MG, CEP: 36571-000.

${ }^{3}$ Departamento de Nutrição e Produção Animal da Faculdade de Medicina Veterinária e Zootecnia/USP, Campus de Pirassununga, Pirassununga, SP, CEP: 13635-900.

${ }^{4}$ Curso de Graduação, Departamento de Zootecnia da Universidade Federal de Viçosa, Campus Universitário, Viçosa, MG, CEP: $36571-000$

${ }^{5}$ Mestrando do Departamento de Nutrição e Produção Animal da Faculdade de Medicina Veterinária e Zootecnia/USP, Campus de Pirassununga, Pirassununga, SP.
}

RESUMO - O objetivo neste estudo foi avaliar o desempenho produtivo de vacas leiteiras sob suplementação com óleo de soja durante o período de transição. Foram utilizadas 20 vacas da raça Holandesa, multíparas e gestantes, distribuídas aleatoriamente em duas rações: controle, com 2,5\% de extrato etéreo (EE) na matéria seca (MS); e gordura, com adição de 3,0\% de óleo de soja e 5,5\% de EE na MS. Os valores médios de consumo de MS e nutrientes não diferiram no período pré e pós-parto nas vacas das dietas controle e com óleo de soja, exceto no maior consumo de EE, em decorrência da maior concentração desse nutriente na dieta com óleo. Em virtude da maior densidade energética da ração com óleo de soja, as vacas apresentaram maior consumo de nutrientes digestíveis totais e energia líquida no pós-parto. Não foi observada alteração nas produções de leite e gordura, no entanto, observou-se redução do teor de gordura do leite nas vacas da ração com óleo de soja em relação àquelas da ração controle. As rações utilizadas não influenciaram o consumo, mas a dieta com óleo de soja aumentou a ingestão de energia líquida e melhorou o balanço de nutrientes no início da lactação. Foi observado aumento não-significativo (+ 2,53 kg/dia) na produção de leite das vacas da dieta com óleo de soja.

Palavras-chave: consumo de matéria seca, desempenho produtivo, gordura dietética, periparto

\section{Use of soybean oil for dairy cows during transition period: Intake, milk yield and composition}

\begin{abstract}
The objective of this study was to evaluate the productivity of dairy cows supplemented with soybean oil during the transition period. Twenty multiparous and pregnant Holstein cows were randomly allocated to two diets: control (C), 2.5\% ether extract (EE) in the dry matter (DM); and fat (G), with the addition of 3\% soybean oil, and 5.5\% $\mathrm{EE}$ in the dry matter. The average values for intake were not different in the pre- and post-partum for cows on the control and fat diets except for an increase in EE intake due to great concentration of this nutrient in the soybean oil diet. Due to the higher energy density of the fat diet, cows had higher intake of total digestible nutrients and net lactation energy during the post-partum. There was no alteration in milk and fat yield, but a reduction in the milk fat content was observed for cows fed fat diet compared with the control diet. The diets used had no influence on the intake, and the fat diet resulted in an increased net energy intake and improvement in the nutrient balance during the initial phase of lactation. A nonsignificant increase in milk yield $(+2.53 \mathrm{~kg} / \mathrm{d})$ was observed when using the fat diet.
\end{abstract}

Key Words: dietary fat, dry matter intake, peripartum, productive performance

\section{Introdução}

O período de transição ou periparto em vacas leiteiras é o tempo entre as últimas três semanas anteriores ao parto até as três primeiras semanas de lactação (Grummer, 1995). Após o parto, a produção de leite e o consumo de alimentos aumentam consideravelmente em vacas leiteiras. No entanto, a velocidade de aumento na produção de leite é maior que a do aumento no consumo de alimentos e nutrientes (Tamminga et al., 1997), o que resulta em períodos de balanço negativo de nutrientes no periparto (Bell, 1995).

Para atender o estado de balanço negativo de nutrientes, principalmente energia, ocorrem adaptações no uso e na conservação da energia no organismo da vaca (Bauman \& 
Currie, 1980), baseadas na obtenção de energia a partir de novos compostos, e, ao mesmo tempo, economia na utilização de glicose por alguns tecidos corporais (Herdt, 2000).

A utilização de fontes de gordura suplementar na dieta tem sido prática comum na alimentação de vacas leiteiras, principalmente por permitir melhora no perfil energético desses animais. É utilizada durante o pós-parto para aumentar a densidade calórica da dieta, sem reduzir o conteúdo de fibras, e promover aumento da ingestão de energia e produção de leite (Grummer, 2004).

Segundo o NRC (2001), as respostas produtivas à suplementação de gordura nas dietas de vacas em lactação dependem da dieta basal, do estágio de lactação, do balanço energético, da composição e quantidade da fonte de gordura utilizada. De acordo com Staples et al. (2001), o principal fator para o aumento de produção é a melhor eficiência de utilização da gordura dietética por vacas em lactação. No entanto, segundo o NRC (2001), as variações nas respostas obtidas com a suplementação de gordura dietética para vacas em lactação têm sido relacionadas às alterações no consumo de matéria seca e nutrientes, especialmente por diminuir o consumo de energia. As razões para as reduções de consumo em alguns experimentos com a utilização de gordura suplementar não estão bem definidas (Staples et al., 1998; Allen, 2000).

O objetivo neste estudo foi avaliar o consumo e o desempenho produtivo de vacas leiteiras sob suplementação com óleo de soja durante o período de transição, por meio dos consumos de matéria seca e nutrientes, da produção e da composição do leite, do peso e do escore de condição corporal em vacas de alta produção.

\section{Material e Métodos}

O experimento foi realizado na Unidade de Ensino, Pesquisa e Extensão em Gado de Leite do Departamento de Zootecnia da Universidade Federal de Viçosa, no período de maio de 2003 a abril de 2004.

Foram utilizadas 20 vacas da raça Holandesa, multíparas e gestantes, com parto previsto para 35 dias após o início da avaliação para fornecimento das rações experimentais, avaliadas durante o período pré-parto; ao parto; e até o 600 dia de lactação. Os animais foram alojados em baias individuais providas de cochos e bebedouros, medindo $3 \times 3 \mathrm{~m}$, com palha de arroz ou café como cama. As vacas foram ordenhadas mecanicamente duas vezes ao dia (6 h e 16h30) e alimentadas também duas vezes ao dia (às 7 h e 15 h).
As vacas utilizadas apresentaram aos 28 dias préparto média de $4,15( \pm 2,13)$ partos, peso vivo médio de $712,02( \pm 65,20)$ kg e escore de condição corporal médio de 3,16 $( \pm 0,53)$. Os animais foram selecionados de modo que apresentassem características semelhantes, para melhor distribuição entre as dietas. Na seleção dos animais, foram considerados a produção de leite na lactação anterior, o peso corporal e o escore de condição corporal aos 40 dias pré-parto, a ordem de partos $(\geq 2$ partos), a duração do período seco e o intervalo de partos.

Os animais foram distribuídos aleatoriamente para receber as rações experimentais: controle, com aproximadamente $2,5 \%$ de extrato etéreo ( $\mathrm{n}=10$ vacas); e óleo de soja, com aproximadamente 5,5\% de extrato etéreo, obtido com inclusão de 3,0\% de óleo de soja degomado no concentrado ( $\mathrm{n}=10$ vacas). Foram fornecidos os mesmos níveis de extrato etéreo (\% MS) nas rações durante o experimento, incluindo os períodos pré e pós-parto, e o volumoso utilizado foi a silagem de milho. As rações foram fornecidas na forma de ração total, juntamente com a água, à vontade, durante o período experimental.

As rações experimentais foram fornecidas a partir de 35 dias antes da data prevista para o parto até 60 dias após o parto; foram formuladas conforme recomendações do NRC (2001) para cada período (pré e pós-parto) (Tabela 1) e nível de produção de leite estimado durante o início da lactação, baseado em registros de produções anteriores. No período pré-parto, as características dos animais utilizadas na formulação das rações experimentais foram: peso corporal de 650 kg; 250 dias de gestação; 3,0 partos; escore de condição corporal 3,0; e 60 meses de idade. No período pós-parto, as características consideradas foram: $35 \mathrm{~kg} /$ dia de leite com 3,8\% de gordura e 3,3\% de proteína; 30 dias de lactação; peso corporal de 600 kg; 3,0 partos; escore de condição corporal 2,5; e 60 meses de idade.

As vacas que receberam a ração com óleo de soja foram alimentadas com a ração controle antes do início do período experimental, com substituição parcial da ração controle por aquela com óleo de soja antes da quarta semana préparto. Foi considerado o primeiro dia experimental o início da quarta semana pré-parto, quando cada animal consumiu a ração selecionada. Durante o período pré-parto, as vacas ficaram no mínimo quatro semanas recebendo as rações experimentais antes da data prevista para o parto.

A quantidade de volumoso e concentrado foi ajustada diariamente para a manutenção de 5 a $10 \%$ de sobras da quantidade de matéria seca ofertada. O total de volumoso e concentrado oferecido para cada animal e as sobras do dia anterior foram pesados diariamente. Amostras de silagem e 
das sobras foram coletadas diariamente e armazenadas em sacos plásticos a $-20^{\circ} \mathrm{C}$ durante sete dias, compondo uma amostra semanal. Amostras do concentrado foram coletadas quinzenalmente e armazenadas em sacos plásticos a $-20^{\circ} \mathrm{C}$. Esses procedimentos foram repetidos até o final do período experimental, para análises posteriores.

Nas amostras de alimentos fornecidos e sobras, foram avaliados os teores de matéria seca (MS), matéria orgânica (MO), nitrogênio total (Kjehldal), cinzas, extrato etéreo (EE), nitrogênio insolúvel em detergente neutro, nitrogênio insolúvel em detergente ácido e lignina, de acordo com metodologias descritas por Silva \& Queiroz (2002). O teor de proteína bruta (PB) foi obtido pela multiplicação do teor de nitrogênio total por 6,25. Os teores de fibra em detergente neutro (FDN) e fibra em detergente ácido (FDA) foram obtidos conforme métodos descritos por Van Soest \& Mason (1991), utilizando-se $\alpha$-amilase sem adição de sulfito de sódio na determinação da FDN.

Os carboidratos totais (CT) foram calculados conforme metodologia de Sniffen et al. (1992), os carboidratos nãofibrosos (CNF), como proposto por Hall (2000), os nutrientes

Tabela 1 - Composição em ingredientes e nutricional das rações experimentais durante os períodos pré e pós-parto (\%MS)

\begin{tabular}{|c|c|c|c|c|}
\hline \multirow[t]{2}{*}{ Composição } & \multicolumn{2}{|c|}{ Pré-parto } & \multicolumn{2}{|c|}{ Pós-parto } \\
\hline & Controle $^{1}$ & Gordura $^{2}$ & Controle & Gordura \\
\hline \multicolumn{5}{|l|}{ Ingrediente } \\
\hline Silagem de milho & 81,72 & 81,81 & 45,02 & 45,10 \\
\hline Fubá de milho & 10,77 & 7,49 & 28,93 & 26,04 \\
\hline Farelo de soja $-48 \%$ PB & 4,95 & 4,70 & 22,35 & 21,71 \\
\hline Óleo de soja & - & 3,30 & - & 3,25 \\
\hline Uréia & 1,19 & 1,33 & - & 0,21 \\
\hline Núcleo mineral & 1,10 & 1,10 & 3,02 & 3,02 \\
\hline Sulfato de amônio & 0,16 & 0,16 & - & - \\
\hline Premix vitamínico & 0,12 & 0,12 & 0,03 & 0,03 \\
\hline Bicarbonato de sódio & - & - & 0,65 & 0,64 \\
\hline \multicolumn{5}{|l|}{ Nutricional } \\
\hline Proteína bruta & 12,3 & 12,3 & 17,7 & 17,7 \\
\hline $\begin{array}{l}\text { Proteína degradável } \\
\text { no rúmen }{ }^{3}\end{array}$ & 9,6 & 9,8 & 11,0 & 11,3 \\
\hline $\begin{array}{l}\text { Proteína não-degradável } \\
\text { no rúmen }{ }^{3}\end{array}$ & 2,7 & 2,5 & 6,7 & 6,4 \\
\hline Fibra em detergente neutro & o 45,9 & 45,6 & 29,4 & 29,1 \\
\hline Fibra em detergente ácido & 26,4 & 26,3 & 16,6 & 16,5 \\
\hline Extrato etéreo & 2,1 & 5,3 & 2,4 & 5,5 \\
\hline Carboidratos não-fibrosos & 35,1 & 32,3 & 43,7 & 40,9 \\
\hline $\mathrm{NDT}_{1 \mathrm{x}}$ & 62,0 & 66,0 & 70,0 & 73,0 \\
\hline Energia líquida ${ }^{4}$ & 1,42 & 1,54 & 1,61 & 1,71 \\
\hline
\end{tabular}

\footnotetext{
${ }^{1}$ Ração com aproximadamente $2,5 \%$ de extrato etéreo na MS.

2 Ração com aproximadamente 5,5\% de extrato etéreo na MS, baseado na inclusão de 3,0\% de óleo de soja degomado.

$3 \%$ proteína bruta, calculadas utilizando o NRC (2001).

${ }^{4}$ Mcal por kg de matéria seca.
}

digestíveis totais (NDT) e a estimativa do valor de energia líquida (EL) das rações, por meio do NRC (2001).

O escore de condição corporal (ECC) e o peso corporal foram avaliados durante todo o período experimental. As mensurações do ECC foram realizadas a intervalos quinzenais, por um técnico treinado, segundo metodologia proposta por Edmonson et al. (1989), a partir de uma escala biológica de 1 a 5 , com subunidades de 0,25 pontos. Os animais foram pesados semanalmente em balança para bovinos, durante dois dias consecutivos, logo após a ordenha da manhã, e no dia do parto (nas primeiras 24 horas pós-parto). Foram avaliadas as mudanças de peso durante o período pré-parto, ao parto e em todo o período pós-parto.

O balanço de energia foi calculado de acordo com o consumo de nutrientes dos animais e as estimativas de exigências nutricionais, utilizando o NRC (2001). O balanço de energia foi calculado da seguinte forma: ingestão de EL - exigência EL para mantença - exigência EL para produção de leite.

A produção de leite foi medida diariamente, com amostras de leite coletadas semanalmente para avaliação do teor de gordura, compreendendo amostras proporcionais das ordenhas realizadas diariamente de manhã e à tarde. A produção de leite também foi corrigida para 3,5\% de gordura (PLC) para posterior avaliação, segundo fórmula descrita por Sklan et al. (1994): PLC = produção de leite $\times(0,432+$ $0,163 \times$ teor de gordura do leite).

Foi utilizado um delineamento inteiramente ao acaso, com os animais distribuídos aleatoriamente entre as rações experimentais (controle e óleo de soja). O consumo de MS e nutrientes (PB, FDN, CNF, CT, MO, EE, NDT e EL), a produção de leite, a produção de leite corrigida para 3,5\% de gordura, a produção e o teor de gordura do leite, o escore de condição corporal e a mudança de condição corporal, o peso corporal e a mudança de peso corporal foram analisados pelo procedimento PROC MIXED (SAS, 1999), utilizando modelo linear misto para medidas repetidas no tempo. Esse procedimento permitiu melhor ajuste na estrutura da matriz que descreve as covariâncias de medidas repetidas no tempo. Na avaliação dessas variáveis, foram considerados os efeitos fixos da suplementação com óleo de soja (rações experimentais), semanas em cada período (pré ou pós-parto) e interação tratamento $\times$ semanas. $\mathrm{O}$ efeito de vacas dentro de classes foram considerados aleatórios. As médias ajustadas (LSmeans) dos efeitos fixos foram comparadas pelo procedimento PDIFF do SAS, pelo teste Tukey.

O peso corporal e a variação do peso corporal foram avaliados no período pré-parto considerando a mudança de 
peso dos 28 aos 3 dias pré-parto, no dia do parto, que incluiu a mudança de peso imediatamente antes do parto e o peso no dia do parto (primeiras 24 horas pós-parto), e no período pós-parto, considerando o peso após o parto em relação aos dias avaliados até os 60 dias pós-parto. Na análise da mudança de peso corporal, em virtude das diferenças no peso corporal no início do período experimental, o peso aos 28 dias pré-parto e o peso após o parto foram utilizados como covariáveis. Em todas as análises estatísticas efetuadas, a diferença foi considerada significativa quando $\mathrm{P}<0,05$, considerando tendência quando $\mathrm{P}<0,10$.

\section{Resultados e Discussão}

Os consumos de matéria seca e de nutrientes (PB, FDN, CNF, CT, MO, EE, NDT e EL), exceto EE, no período pré-parto não diferiram $(\mathrm{P}>0,05)$ entre as vacas alimentadas com as rações controle e com óleo de soja. Diferenças também não foram observadas $(\mathrm{P}>0,05)$ nos consumos de matéria seca e de nutrientes, exceto EE, NDT e EL, no período pós-parto $(\mathrm{P}<0,05)$. Na média, as vacas alimentadas com as rações controle e com óleo de soja consumiram $10,73 \pm 2,87$ e $9,95 \pm 1,80 \mathrm{~kg}$ MS por dia no pré-parto e $16,02 \pm 3,71$ e 17,80 $\pm 3,62 \mathrm{~kg}$ de MS por dia no pós-parto, respectivamente (Tabelas 2 e 3 ).

Como previsto, as vacas alimentadas com a ração com óleo de soja consumiram maior quantidade de extrato etéreo $(\mathrm{P}<0,01)$ nos períodos pré e pós-parto. Foi observado consumo de EE no pré-parto e pós-parto para as vacas alimentadas com as rações controle e com óleo de soja, de $0,234 \pm 0,08$ e $0,408 \pm 0,09$ kg e $0,607 \pm 0,09$ e $1,02 \pm 0,22 \mathrm{~kg}$ de EE por dia, respectivamente. Houve tendência de as vacas submetidas à ração controle consumirem maior quantidade de carboidratos não-fibrosos $(\mathrm{P}=0,085)$ durante o período pré-parto, provavelmente em razão da maior concentração de carboidratos não-fibrosos nas rações com óleo de soja, o que não ocorreu no período pós-parto.

Como a composição das rações controle e com óleo de soja foi similar (Tabela 1), com diferença especialmente na concentração de EE, a ração com óleo de soja apresentou maior densidade energética, de 0,12 Mcal EL/kg MS no período pré-parto (+ 8,45\%) e de 0,10 EL/kg MS no período

Tabela 2 - Consumo de nutrientes, nutrientes digestíveis totais e energia líquida no período pré-parto

\begin{tabular}{|c|c|c|c|c|c|c|}
\hline \multirow[t]{2}{*}{ Nutriente } & \multirow[t]{2}{*}{ Ração } & \multicolumn{4}{|c|}{ Semana pré-parto ${ }^{2}$} & \multirow[t]{2}{*}{ Média } \\
\hline & & 4 & 3 & 2 & 1 & \\
\hline \multirow[t]{2}{*}{ Matéria $\operatorname{seca}^{3}(\mathrm{~kg} / \mathrm{dia})$} & Controle & 11,95 & 11,77 & 10,70 & 8,86 & 10,73 \\
\hline & Gordura & 10,97 & 10,72 & 9,70 & 8,61 & 9,95 \\
\hline \multirow{2}{*}{ Matéria seca (\%PV) } & Controle & 1,72 & 1,65 & 1,49 & 1,25 & 1,51 \\
\hline & Gordura & 1,54 & 1,42 & 1,34 & 1,20 & 1,37 \\
\hline \multirow[t]{2}{*}{ Matéria orgânica (kg/dia) } & Controle & 11,51 & 11,26 & 10,20 & 8,45 & 10,27 \\
\hline & Gordura & 10,29 & 10,05 & 9,09 & 8,06 & 9,32 \\
\hline \multirow[t]{2}{*}{ Proteína bruta (kg/dia) } & Controle & 1,61 & 1,54 & 1,42 & 1,34 & 1,47 \\
\hline & Gordura & 1,42 & 1,39 & 1,27 & 1,26 & 1,33 \\
\hline \multirow[t]{2}{*}{ Fibra em detergente neutro (kg/dia) } & Controle & 5,46 & 5,45 & 4,92 & 3,86 & 4,88 \\
\hline & Gordura & 4,93 & 4,83 & 4,30 & 3,62 & 4,40 \\
\hline \multirow[t]{2}{*}{ Carboidratos não fibrosos (kg/dia) } & Controle & $4,16 \mathrm{c}$ & $4,00 c$ & $3,61 c$ & 3,00 & 3,66 \\
\hline & Gordura & $3,29 d$ & $3,20 d$ & $2,94 d$ & 2,58 & 2,99 \\
\hline \multirow[t]{2}{*}{ Carboidratos totais (kg/dia) } & Controle & 9,62 & 9,45 & 8,53 & 6,91 & 8,55 \\
\hline & Gordura & 8,23 & 8,03 & 7,24 & 6,20 & 7,38 \\
\hline \multirow[t]{2}{*}{ Extrato etéreo (kg/dia) } & Controle & $0,27 b$ & $0,26 b$ & $0,23 b$ & $0,19 b$ & 0,23 \\
\hline & Gordura & $0,64 \mathrm{a}$ & $0,62 \mathrm{a}$ & $0,58 \mathrm{a}$ & $0,59 a$ & 0,61 \\
\hline \multirow[t]{2}{*}{ Nutrientes digestíveis totais (kg/dia) } & Controle & 7,47 & 7,36 & 6,68 & 5,53 & 6,71 \\
\hline & Gordura & 7,18 & 6,98 & 6,36 & 5,66 & 6,51 \\
\hline \multirow[t]{2}{*}{ Energia líquida (Mcal/dia) } & Controle & 16,96 & 16,76 & 15,32 & 12,93 & 15,38 \\
\hline & Gordura & 17,04 & 16,60 & 15,14 & 13,52 & 15,50 \\
\hline
\end{tabular}

\footnotetext{
${ }^{1}$ Rações pré-parto: controle, com 2,1\% de EE na MS; e gordura, com 5,3\% de EE na MS

2 Semana 4 a 1 se refere a quarta até primeira semana antes do parto.

3 Médias com letras na coluna diferem a 5\% (a,b) ou 10\% (c,d) de significância.
} 
Tabela 3 -Consumo de nutrientes, nutrientes digestíveis totais e energia líquida no período pós-parto

\begin{tabular}{|c|c|c|c|c|c|c|c|c|c|c|c|}
\hline \multirow[t]{2}{*}{ Nutriente } & \multirow[t]{2}{*}{ Ração } & \multicolumn{9}{|c|}{ Semana pós-parto ${ }^{2}$} & \multirow[t]{2}{*}{ Média } \\
\hline & & 1 & 2 & 3 & 4 & 5 & 6 & 7 & 8 & 9 & \\
\hline Matéria seca $^{3}$ (kg/dia) & Controle & 12,34 & 14,34 & 15,10 & 15,53 & 16,70 & 17,84 & 17,81 & 16,98 & 17,58 & 16,02 \\
\hline \multirow[t]{2}{*}{ Matéria seca (\%PV) } & Controle & 1,97 & 2,36 & 2,56 & 2,69 & 2,92 & 3,12 & 3,13 & 2,99 & 3,10 & 2,76 \\
\hline & Gordura & 2,06 & 2,57 & 2,90 & 3,12 & 3,17 & 3,22 & 3,30 & 3,43 & 3,34 & 3,01 \\
\hline Matéria orgânica (kg/dia) & Gordura & 12,03 & 14,42 & 15,88 & 16,80 & 16,97 & 17,20 & 17,67 & 18,39 & 17,86 & 16,36 \\
\hline \multirow[t]{2}{*}{ Proteína bruta (kg/dia) } & Controle & 2,23 & 2,58 & 2,73 & 2,81 & 3,02 & 3,24 & 3,18 & 3,03 & 3,15 & 2,89 \\
\hline & Gordura & 2,25 & 2,69 & 2,96 & 3,13 & 3,15 & 3,20 & 3,27 & 3,41 & 3,32 & 3,04 \\
\hline Fibra em detergente neutro (kg/dia) & Controle & 3,74 & 4,31 & 4,54 & 4,60 & 4,90 & 5,26 & 5,32 & 4,97 & 5,32 & 4,78 \\
\hline \multirow[t]{2}{*}{ Carboidratos totais (kg/dia) } & Controle & 9,28 & 10,78 & 11,39 & 11,67 & 12,54 & 13,50 & 13,54 & 12,77 & 13,29 & 12,09 \\
\hline & Gordura & 9,03 & 10,82 & 11,91 & 12,61 & 12,74 & 12,92 & 13,30 & 13,85 & 13,43 & 12,29 \\
\hline \multirow[t]{2}{*}{ Extrato etéreo (kg/dia) } & Controle & $0,31 b$ & $0,37 b$ & $0,39 b$ & $0,41 b$ & $0,43 \mathrm{~b}$ & $0,45 b$ & $0,44 b$ & $0,42 b$ & $0,43 b$ & 0,41 \\
\hline & Gordura & $0,76 \mathrm{a}$ & $0,90 \mathrm{a}$ & 0,99 a & $1,06 \mathrm{a}$ & $1,07 \mathrm{a}$ & $1,07 a$ & $1,09 \mathrm{a}$ & $1,13 \mathrm{a}$ & $1,10 \mathrm{a}$ & 1,02 \\
\hline \multirow[t]{2}{*}{ Nutrientes digestíveis totais ( $\mathrm{kg} /$ dia) } & Controle & 8,65 & $9,47 d$ & $10,61 b$ & $10,93 b$ & $11,78 b$ & 12,54 & 12,40 & $11,82 b$ & 12,26 & 11,16 \\
\hline & Gordura & 9,59 & $11,52 \mathrm{c}$ & $12,67 \mathrm{a}$ & $13,35 a$ & $13,51 \mathrm{a}$ & 13,68 & 14,02 & $14,59 a$ & 14,15 & 13,01 \\
\hline \multirow[t]{2}{*}{ Energia líquida (Mcal/dia) } & Controle & 20,93 & $23,96 \mathrm{~d}$ & $24,99 b$ & $25,58 b$ & $27,31 b$ & 28,74 & 28,65 & $28,95 b$ & 28,22 & 26,37 \\
\hline & Gordura & 23,67 & $27,63 c$ & $29,97 a$ & $31,36 a$ & $32,94 a$ & 31,95 & 32,57 & $33,71 \mathrm{a}$ & 32,61 & 30,71 \\
\hline
\end{tabular}

${ }^{1}$ Rações pré-parto: controle, com 2,4\% de EE na MS; e gordura, com 5,5\% de EE na MS.

2 Semana 1 a 9 se refere a primeira e nona semana pós-parto.

${ }^{3}$ Médias com letras na coluna diferem a 5\% (a,b) ou $10 \%$ (c,d) de significância.

pós-parto (+ 6,21\%) em relação à ração controle. As vacas alimentadas com a ração com óleo de soja apresentaram tendência de maior consumo no período pós-parto quando avaliadas no tempo (interação ração $\times$ tempo), calculado em $\mathrm{kg} / \mathrm{dia}(\mathrm{P}=0,091)$ e em $\% \mathrm{PV}(\mathrm{P}=0,097)$. Em virtude do maior consumo de MS, os consumos de NDT e EL foram maiores no período pós-parto $(\mathrm{P}<0,05)$ para as vacas alimentadas com a ração com óleo de soja (Tabela 3).

Em estudos realizados por Malafaia et al. (1996) e Pereira et al. (1998) com rações com aproximadamente 5,5\% de extrato etéreo na MS, também não foram observadas alterações no consumo de matéria seca e nutrientes, que não foram influenciados pelas fontes de lipídios utilizadas no concentrado. Nesses estudos, o consumo de extrato etéreo aumentou com a inclusão da fonte de gordura nas rações.

Segundo Allen (2000), a fonte de gordura suplementar influencia as alterações no consumo de matéria seca, uma vez que a magnitude de redução no consumo com a utilização de óleos vegetais é bem menor que a observada com outras fontes de gordura, como os sais de cálcio de ácidos graxos e gorduras não-processadas. De modo geral, apesar das reduções no consumo quando são utilizadas fontes de gordura suplementar em rações para vacas leiteiras, especialmente em lactação, não são observadas diferenças no consumo quando a fonte de gordura é misturada no concentrado de forma satisfatória ou quando os animais são adaptados previamente ao fornecimento da fonte de gordura suplementar (NRC, 2001). Assim, a adaptação dos animais às dietas contendo gordura suplementar pode auxiliar na manutenção de níveis adequados de consumo e na obtenção dos benefícios da utilização de gordura dietética (Staples et al., 1998).

Neste estudo houve efeito de tempo nos dois períodos para todas as variáveis relacionadas ao consumo de matéria seca e de nutrientes, com diminuição desses parâmetros no período pré-parto e aumento no período pós-parto (Figura 1). O consumo de matéria seca reduziu 22,75 e $17,68 \%$ na última semana pré-parto, em comparação às semanas anteriores, para as vacas alimentadas com as rações controle e com óleo de soja, respectivamente. 
Bertics et al. (1992) observaram redução no consumo de matéria seca entre 20 e 30\% na última semana pré-parto. Segundo Grummer (1995), um dos fatores relacionados à redução de consumo é a alteração da concentração sanguínea de diversos hormônios que aumentam ou diminuem drasticamente no periparto. Esse autor sugeriu que estes hormônios podem ser potentes modificadores do consumo e que o estrógeno ou a proporção entre estrógeno e progesterona influenciam o consumo no período pré-parto.

Limitações físicas, decorrentes do crescimento fetal, também têm sido apontadas como causas da diminuição do consumo com a proximidade do parto (Agenas et al., 2003). Segundo Bertics et al. (1992), outra possível explicação para a redução no consumo alguns dias pré-parto está associada ao aumento da infiltração de gordura no fígado.

No período pós-parto, houve rápido aumento do consumo de matéria seca em ambos os grupos (Figura 1). Neste estudo, a taxa de aumento no consumo de matéria seca entre a primeira e terceira semana foi de 1,38 e 2,08 kg por semana para os animais alimentados com as rações controle e com óleo de soja, respectivamente. Esses valores estão próximos aos citados por Bertics et al. (1992), que obtiveram aumento de 1,5 a $2,5 \mathrm{~kg} / \mathrm{semana}$ durante as primeiras três semanas de lactação.

Não foi observado efeito $(\mathrm{P}>0,05)$ das rações experimentais sobre a produção de leite, a produção de leite corrigida e a produção de gordura (Tabela 5). A produção de leite e a produção de leite corrigida para 3,5\% de gordura foram influenciadas pelo tempo $(\mathrm{P}<0,01)$ nas duas rações

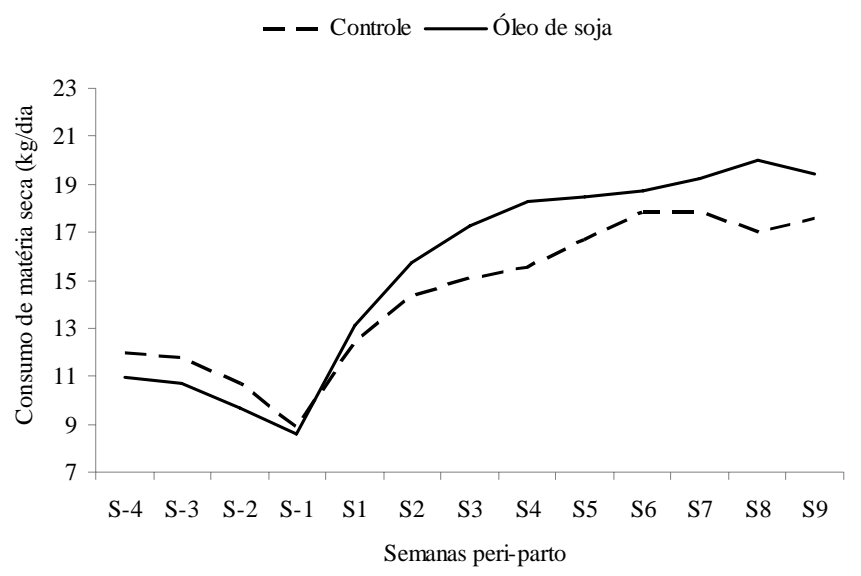

Figura 1 - Consumo de matéria seca (CMS) durante o pré e o pósparto de vacas alimentadas com dietas controle e com óleo de soja. S-4 até S-1 representam semanas relacionadas ao pré-parto e S1 até S9 representam semanas relacionadas ao pós-parto.

utilizadas, uma vez que, como esperado, as médias de produção aumentaram com o avançar das semanas em lactação. O teor e produção de gordura também foram influenciados, pois foi observada redução do teor e da produção de gordura com o avançar da lactação.

Durante as nove primeiras semanas de lactação, as produções de leite médias dos animais mantidos com as rações controle e com óleo de soja foram de 31,88 \pm 5,06 e $34,41 \pm 6,51 \mathrm{~kg} /$ dia, respectivamente. As vacas alimentadas com a ração com óleo de soja produziram 2,53 kg/dia a mais de leite que aquelas da ração controle (7,93\%). A média de

Tabela 4 - Balanço de energia, escore de condição corporal (ECC) e mudança de ECC, peso corporal e mudança de peso corporal no período pré-parto e ao parto

\begin{tabular}{|c|c|c|c|c|c|c|c|}
\hline \multirow[t]{2}{*}{ Item } & \multirow[t]{2}{*}{ Ração } & \multicolumn{4}{|c|}{ Semana Pré-parto ${ }^{2}$} & \multirow[t]{2}{*}{ Média pré-parto } & \multirow[t]{2}{*}{ Parto $^{3}$} \\
\hline & & 4 & 3 & 2 & 1 & & \\
\hline \multirow[t]{2}{*}{ Balanço de energia (Mcal/dia) } & Controle & 3,44 & 2,93 & 1,45 & $-0,84$ & 1,62 & - \\
\hline & Gordura & 3,32 & 2,69 & 1,14 & $-0,46$ & 1,59 & - \\
\hline \multirow[t]{2}{*}{ ECC (unidade) } & Controle & 3,25 & 3,24 & 3,15 & 3,15 & 3,19 & - \\
\hline & Gordura & 3,19 & 3,11 & 3,12 & 3,14 & 3,14 & - \\
\hline \multirow[t]{2}{*}{ Mudança ECC (unidade) } & Controle & - & 0,048 & 0,025 & 0,028 & 0,033 & - \\
\hline & Gordura & - & 0,012 & 0,025 & 0,039 & 0,026 & - \\
\hline \multirow[t]{2}{*}{ Peso corporal(kg) } & Controle & 704,3 & 707,8 & 716,1 & 713,3 & 695,2 & 635,2 \\
\hline & Gordura & 719,0 & 723,8 & 725,8 & 729,4 & 710,8 & 656,5 \\
\hline \multirow[t]{2}{*}{ Mudança de peso corporal (kg) } & Controle & - & 7,07 & 14,05 & 13,15 & 11,42 & $-74,28$ \\
\hline & Gordura & - & 4,17 & 5,38 & 9,03 & 6,19 & $-74,90$ \\
\hline
\end{tabular}

${ }^{1}$ Rações pré-parto controle (C), com EE = 2,1\% MS, e gordura (G), com EE = 5,3\% MS.

2 Semana 4 a 1 se refere a quarta até primeira semana antes do parto.

${ }^{3}$ Peso corporal nas primeiras 24 horas pós-parto.

${ }^{4}$ Médias com letras na coluna diferem a 5\% (a,b) ou 10\% (c,d) de significância. 
produção de leite corrigida das vacas alimentadas com as rações controle e com óleo de soja foram de 36,34 \pm 6,29 e $36,02 \pm 8,30 \mathrm{~kg} /$ dia, respectivamente, e não diferiu $(\mathrm{P}>0,05)$ entre os dois grupos de animais.

Apesar de não-significativo, o aumento da produção de leite pode estar relacionado à maior ingestão de energia (NDT e energia líquida) pelas vacas alimentadas com ração com óleo de soja, principalmente a partir da terceira semana de lactação. De acordo com Onetti \& Grummer (2004), a resposta positiva à suplementação de gordura dietética deve ser esperada, em virtude da maior disponibilidade de energia líquida, desde que não ocorra redução no consumo de matéria seca.

Em trabalho de revisão, Jenkins (1993) indicou que a máxima resposta em produção de leite à suplementação com lipídios foi de 3,5 kg por dia e que foram necessários aproximadamente 700 gramas de gordura suplementar para sustentar essa produção. Neste estudo o consumo de extrato etéreo foi $0,612 \mathrm{~kg}$ maior para as vacas alimentadas com a ração com óleo de soja, o que ocasionou aumento de 2,53 kg de leite por dia, confirmando os estudos revisados por esse autor.
O teor de gordura no leite diferiu $(\mathrm{P}<0,05)$ entre as vacas submetidas às rações experimentais e foi significativo a partir da quarta semana de lactação, quando a diferença na produção total de leite se tornou expressiva (Tabela 5). As médias do teor de gordura do leite ao final do período experimental foram de 4,37 $\pm 0,79$ e 3,81 $\pm 1,08 \%$ para os animais alimentados com as rações controle e com óleo de soja, respectivamente (redução de 0,56\%). Essa diferença pode estar relacionada à maior produção de leite nesse período para os animais mantidos com a ração com óleo de soja, visto que, quanto maior o volume de leite, menor a concentração por mililitro de seus constituintes. Contudo, essa redução do teor de gordura foi compensada pela maior produção diária de leite, resultando na ausência de efeito das rações sobre a produção de gordura. As produções médias de gordura foram de 1,38 $\pm 0,29$ e 1,30 $\pm 0,40 \mathrm{~kg} /$ dia para os grupos alimentados com as rações controle e com óleo de soja, respectivamente.

Schingoethe \& Casper (1991) e Pantoja et al. (1994) citaram que o fornecimento de fontes de gordura insaturadas pode aumentar a probabilidade de alterações no teor de gordura do leite. Normalmente estas alterações

Tabela 5 - Produção de leite, produção de leite corrigida a 3,5\% de gordura, teor e produção de gordura no leite, balanço de energia, escore de condição corporal (ECC) e mudança de ECC, peso corporal e mudança de peso corporal, no período pós-parto

\begin{tabular}{|c|c|c|c|c|c|c|c|c|c|c|c|}
\hline \multirow[t]{2}{*}{ Nutriente } & \multirow[t]{2}{*}{ Ração } & \multicolumn{9}{|c|}{ Semana de lactação ${ }^{2}$} & \multirow[t]{2}{*}{ Média } \\
\hline & & 1 & 2 & 3 & 4 & 5 & 6 & 7 & 8 & 9 & \\
\hline \multirow[t]{2}{*}{ Produção de leite (kg/dia) } & Controle & 25,6 & 32,1 & 33,6 & 32,0 & 33,2 & 33,7 & 33,3 & $31,8 d$ & 31,3 & 31,9 \\
\hline & Gordura & 27,2 & 32,2 & 34,1 & 35,1 & 35,8 & 35,9 & 36,6 & $37,3 c$ & 35,4 & 34,4 \\
\hline \multirow[t]{2}{*}{ Produção de leite corrigida (kg/dia) } & Controle & 31,8 & 39,5 & 40,8 & 37,6 & 35,8 & 36,3 & 35,7 & 34,5 & 35,3 & 36,3 \\
\hline & Gordura & 34,5 & 40,4 & 38,7 & 36,5 & 35,3 & 36,0 & 33,7 & 35,3 & 33,7 & 36,0 \\
\hline \multirow[t]{2}{*}{ Gordura do leite (\%) } & Controle & 4,89 & 4,88 & 4,74 & $4,56 a$ & $4,00 \mathrm{a}$ & 3,95 & $3,94 a$ & 4,05a & $4,29 a$ & 4,37 \\
\hline & Gordura & 5,12 & 5,04 & 4,28 & 3,69b & $3,40 \mathrm{~b}$ & 3,55 & $2,95 b$ & $3,11 b$ & $3,14 b$ & 3,81 \\
\hline \multirow[t]{2}{*}{ Produção gordura do leite (kg/dia) } & Controle & 1,25 & 1,58 & 1,61 & 1,46 & 1,31 & 1,33 & 1,30 & 1,27 & 1,34 & 1,38 \\
\hline & Gordura & 1,39 & 1,62 & 1,47 & 1,31 & 1,21 & 1,26 & 1,10 & 1,18 & 1,13 & 1,30 \\
\hline \multirow[t]{2}{*}{ Balanço de energia (Mcal/dia) } & Controle & $-10,5$ & $-12,4$ & $-12,0 \mathrm{~d}$ & $-9,1 b$ & $-6,5 d$ & $-5,3$ & $-5,0$ & $-3,8$ & $-4,9 d$ & $-7,7$ \\
\hline & Gordura & $-9,4$ & $-9,1$ & $-5,8 c$ & $-3,0 \mathrm{a}$ & $-0,8 c$ & $-2,3$ & $-0,7$ & $-0,2$ & $0,9 \mathrm{c}$ & $-3,4$ \\
\hline \multirow[t]{2}{*}{ ECC (unidade) } & Controle & 3,07 & 2,93 & 2,70 & 2,63 & 2,57 & 2,48 & 2,44 & 2,40 & 2,40 & 2,62 \\
\hline & Gordura & 3,06 & 2,87 & 2,73 & 2,65 & 2,62 & 2,57 & 2,54 & 2,51 & 2,50 & 2,67 \\
\hline \multirow[t]{2}{*}{ Mudanca ECC (unidade) } & Controle & $-0,02$ & $-0,15$ & $-0,37$ & $-0,46$ & $-0,52$ & $-0,61$ & $-0,65$ & $-0,70$ & $-0,70$ & $-0,46$ \\
\hline & Gordura & $-0,06$ & $-0,24$ & $-0,41$ & $-0,50$ & $-0,53$ & $-0,57$ & $-0,60$ & $-0,64$ & $-0,65$ & $-0,47$ \\
\hline \multirow[t]{2}{*}{ Peso corporal (kg) } & Controle & 636,3 & 619,3 & 598,7 & 582,8 & 574,8 & 574,0 & 571,0 & 568,7 & 565,5 & 587,9 \\
\hline & Gordura & 647,2 & 615,2 & 598,2 & 588,5 & 583,2 & 580,5 & 582,6 & 582,0 & 582,5 & 595,5 \\
\hline \multirow[t]{2}{*}{ Mudança no peso corporal (kg) } & Controle & $-4,80$ & $-21,7$ & $-38,7$ & $-55,7$ & $-63,6$ & $-66,3$ & $-68,8$ & $-71,3$ & $-74,3$ & $-51,7$ \\
\hline & Gordura & $-5,48$ & $-35,8$ & $-53,7$ & $-63,9$ & $-69,6$ & $-73,4$ & $-71,1$ & $-72,0$ & $-70,9$ & $-57,3$ \\
\hline
\end{tabular}

${ }^{1}$ Rações pré-parto controle (C), com $\mathrm{EE}=2,4 \% \mathrm{MS}$, e gordura (G), com $\mathrm{EE}=5,5 \% \mathrm{MS}$

2 Semana 1 a 9 se refere a primeira e nona semana pós-parto.

${ }^{3}$ Médias com letras na coluna diferem a 5\% (a,b) ou $10 \%$ (c,d) de significância. 
são atribuídas a um impacto negativo que as gorduras insaturadas podem ter na digestão da fibra no rúmen e/ou à maior produção de ácidos graxos trans no rúmen, em razão da biohidrogenação incompleta de ácidos graxos insaturados, comprometendo a síntese de novo de ácidos graxos na glândula mamária (Bauman \& Griinari, 2001). Os ácidos graxos trans são compostos intermediários do processo de biohidrogenação ruminal de gorduras insaturadas por microrganismos ruminais (Bauman \& Griinari, 2001). O aumento da absorção dos ácidos graxos trans no sangue induz à diminuição do teor de gordura do leite.

Não houve efeito das rações no escore de condição corporal (ECC) e na mudança de ECC nos períodos pré e pósparto $(\mathrm{P}>0,05)$ (Tabelas $4 \mathrm{e} 5)$. Ao parto, as vacas alimentadas com as rações controle e com óleo de soja apresentaram ECC médio de 3,14 e 3,15 unidades, respectivamente. Foi observado efeito das semanas de lactação $(\mathrm{P}<0,01)$ durante o período pós-parto na mudança de ECC, que foi de -0,70 e -0,65 unidades para as vacas das rações controle e com óleo de soja, respectivamente. Essa diminuição do ECC está dentro dos valores normais citados pelo NRC (2001) para vacas leiteiras nos primeiros 60 dias após o parto.

Não foi observado efeito das rações experimentais no peso corporal e na mudança de peso corporal nos períodos pré e pós-parto $(\mathrm{P}>0,05)$. Os pesos corporais das vacas após o parto, para as dietas controle e com óleo de soja, foram de 640,10 e 651,33 kg. Ao final do período experimental o peso corporal dos animais dos grupos controle e com óleo de soja foi de 565,46 e 582,46 kg, e a mudança de peso corporal foi de $-74,30$ e $-70,88 \mathrm{~kg}$, respectivamente (Tabelas 4 e 5).

As vacas ao parto reduziram em média 75,50 kg de seu peso e esta diminuição está relacionada à expulsão do feto, da placenta e dos demais conteúdos uterinos, e ao início do catabolismo de reservas corporais, representando 10,46\% do peso vivo. No período pós-parto, foi observada rápida diminuição no peso corporal, refletindo primariamente o intenso catabolismo de reservas corporais para o fornecimento de energia para a produção de leite que ocorre no início da lactação (Komaragiri et al., 1998). Os valores de mudança de peso corporal para as vacas ao parto e no período pós-parto foram semelhantes às médias observadas por Rennó et al. (2006).

Neste estudo foi avaliado o balanço de energia utilizando a mensuração do consumo de nutrientes e a estimativa das exigências nutricionais. Não houve diferença entre as vacas mantidas com as rações controle e com óleo de soja no período pré-parto $(\mathrm{P}>0,05)$, porém, houve efeito de tempo
$(\mathrm{P}<0,05)$, com redução gradativa do balanço de energia de $+3,38$ para -0,65 Mcal EL/dia de quatro semanas antes do parto para a semana do parto (Tabela 4). Assim, o balanço de energia ficou levemente negativo a partir da semana imediatamente anterior ao parto.

No período pós-parto, as vacas alimentadas com as duas rações apresentaram balanço de energia negativo no início da lactação. As vacas das rações controle e com óleo de soja atingiram o ponto de menor balanço energético negativo, respectivamente, na segunda e primeira semana de lactação (-12,38 e -9,41 Mcal EL/dia, respectivamente) (Tabela 5). Houve tendência $(\mathrm{P}=0,09)$ das vacas submetidas a ração com óleo de soja apresentarem melhor balanço de energia durante o início da lactação em relação às vacas mantidas com a ração controle. Foi verificada interação ração $\times$ semanas de lactação $(P<0,05)$, uma vez que as vacas do grupo controle apresentaram balanço energético negativo mais acentuado, especialmente a partir da terceira semana de lactação.

De forma geral, as vacas alimentadas com a ração contendo óleo de soja apresentaram melhor balanço de energia em comparação àquelas mantidas com a ração controle, com menor magnitude e duração do balanço energético negativo. As vacas do grupo com óleo de soja começaram a melhorar o balanço de energia a partir da terceira semana de lactação, enquanto aquelas do grupo controle somente tiveram alteração da intensidade do balanço de energia a partir da quarta semana, porém com balanço energético negativo mais severo que o das vacas mantidas com a ração com óleo de soja. As vacas da ração com óleo de soja atingiram o balanço positivo de energia na oitava semana, enquanto os animais do grupo controle permaneceram em balanço energético negativo até o término do período experimental.

O melhor balanço de energia das vacas submetidas a ração com óleo de soja está relacionado à manutenção do consumo com o fornecimento de dieta de maior densidade energética. Além disso, a suplementação com gordura resultou em diminuição do teor de gordura do leite, o que tendeu a igualar a excreção de energia do leite quando consideradas a produção de leite e de gordura. Esses resultados estão de acordo com os relatados por BernalSantos et al. (2003) e Selberg et al. (2004), que sugeriram que a diminuição do teor de gordura no leite pode ajudar a reduzir o balanço energético negativo no início da lactação, melhorando o status metabólico de vacas leiteiras neste período, particularmente nas primeiras quatro semanas, tornando-se uma opção de manejo em algumas circunstâncias de produção. 


\section{Conclusões}

A utilização de óleo de soja em rações para vacas no período de transição não influencia o consumo nem o desempenho produtivo, mas aumenta a ingestão de energia e melhora o balanço de nutrientes durante o início da lactação.

\section{Literatura Citada}

AGENAS, S.; BURSTEDT, E.; HOLTENIUS, K. Effects of feeding intensity during the dry period. 1 . Feed intake, body weight, and milk production. Journal of Dairy Science, v.86, n.3, p.870-882, 2003.

ALLEN, M.S. Effects of diet on short-term regulation of feed intake by lactating dairy cattle. Journal of Dairy Science, v.83, n.7, p.1598-1630, 2000.

BAUMAN, D.E.; CURRIE, W.B. Partitioning of nutrients during pregnancy and lactation: A review of mechanisms involving homeostasis and homeorhesis. Journal of Dairy Science, v.62, n.9, 1514-1528, 1980.

BAUMAN, D.E.; GRIINARI, J.M. Regulation and nutritional manipulation of milk fat: low-fat milk syndrome. Livestock Production Science, v.70, n1-2, p.15-29, 2001.

BELL, A.W. Regulation of organic nutrient metabolism during transition from late pregnancy to early lactation. Journal of Animal Science, v.73, n.9, p.2804-2819, 1995.

BERNAL-SANTOS, G.L.; PERFIELD II, J.W.; BARBANO, D.M. et al. Production responses of dairy cows to dietary supplementation with conjugated linoleic acid (CLA) during the transition period and early lactation. Journal of Dairy Science, v.86, n.10, p.3218-3228, 2003.

BERTICS, S.J.; GRUMMER, R.R.; CADORNIGA-VALINO, C. Effect of prepartum dry matter intake on liver triglyceride concentration and early lactation. Journal of Dairy Science, v.75, n.07, p.1914-1922, 1992.

EDMONSON, A.J.; LEAN, I.J.; WEAVER, L.D. Body condition scoring chart for Holstein dairy cows. Journal of Dairy Science, v.72, n.1, p.68-78, 1989.

GRUMMER, R.R. Gordura da dieta: Fonte energética e/ou regulador metabólico? In: NOVOS ENFOQUES NA PRODUÇÃO E REPRODUÇÃO DE BOVINOS, 8., 2004, Uberlândia. Anais... Uberlândia: CONAPEC Jr - UNESPBOTUCATU, 2004. p.83-108.

GRUMMER, R.R. Impact of changes in organic nutrient metabolism on feeding the transition dairy cow. Journal of Animal Science, v.73, n.9, p.2820-2833, 1995.

HALL, M.B. Calculation of non-estructural carbohydrate content of feeds that contain non-protein nitrogen. Gainsville: University of Florida, 2000. 25p. (Bulletin, 339).

HERDT, T.H. Ruminant adaptation to negative energy balance. Veterinary Clinical of North American, v.16, p.215-230, 2000.

JENKINS, T.C. Lipid metabolism in the rumen. Journal of Dairy Science, v.76, n.12, p.3851-3863, 1993.

KOMARAGIRI, M.V.S.; CASPER, D.P.; ERDMAN, R.A. Factors affecting body tissue mobilization in early lactation dairy cows. 2. Effect of dietary fat on mobilization of body fat and protein. Journal of Dairy Science, v.81, n.1, p.169175, 1998.

MALAFAIA, P.A.M.; VALADARES FILHO, S.C.; SILVA, J.F.C. et al. Sebo bovino em rações para vacas em lactação. 1. Consumo dos nutrientes, produção e composição do leite. Revista Brasileira de Zootecnia, v.25, n.1, p.153-165, 1996.

NATIONAL RESEARCH COUNCIL - NRC. Nutrient requirements of dairy cattle. 7.ed. Washington: National Academic Press, 2001. 381p.

ONETTI, S.G.; GRUMMER R.R. Response of lactating cows to three supplemental fat sources as affected by forage in the diet and stage of lactation: a meta-analysis of literature. Animal Feed Science and Technology, v.115, n.1-2, p.65-82, 2004.

PANTOJA, J.; FIRKINS, J.L.; EASTRIDGE, M.L. et al. Effects of fat saturation and source of fiber on site of nutrient digestion and milk production by lactating dairy cows. Journal of Dairy Science, v.77, n.8, p.2341-2356, 1994.

PEREIRA, C.M.A.; SILVA, J.F.C.; VALADARES FILHO, S.C. et al. Grão de soja moído na ração de vacas em lactação. 1. Consumo e digestibilidade dos nutrientes. Revista Brasileira de Zootecnia, v.27, n.6, p.1218-1224, 1998.

RENNÓ, F.P.; PEREIRA, J.C.; SANTOS, A.D.F. et al. Efeito da condição corporal ao parto sobre a produção e composição do leite, curva de lactação e mobilização de reservas corporais em vacas da raça Holandesa. Arquivo Brasileira de Medicina Veterinária e Zootecnia, v.58, n.4, p.220-233, 2006.

STATISTICAL ANALYSIS SYSTEM - SAS. SAS system user's guide - Online Doc. v.8.0, Cary: 1999.

SCHINGOETHE, D.J.; CASPER, D.P. Total lactational response to added fat during early lactation. Journal of Dairy Science, v.74, n.8, p.2617-2622, 1991.

SELBERG, K.T.; LOWE, A.C.; STAPLES, C.R. et al. Production and metabolic response of periparturient Holstein cows to dietary conjugated linoleic acid and trans-octadecenoic acids. Journal of Dairy Science, v.87, n.1, p.158-168, 2004.

SILVA, D.J.; QUEIROZ, A.C. Análise de alimentos: métodos químicos e biológicos. Viçosa, MG: Editora UFV, 2002. 235p.

SKLAN, D.; KAIM, M.; MOALLEM, U. et al. Effect of dietary calcium soaps on milk yield, body weight, reproductive hormones, and fertility in first parity and older cows. Journal of Dairy Science, v.77, n.6, p.1652-1660, 1994.

SNIFFEN, C.J.; O’CONNOR, J.D.; Van SOEST, P.S. Net carbohydrate and protein system for evaluating cattle diets. II. Carbohydrate and protein availability. Journal of Animal Science, v.70, n.11, p.3562-3577, 1992.

STAPLES, C.R.; BURKE, J.M.; THATCHER, W.W. Influence of supplemental fats on reproductive tissues and performance of lactating cows. Journal of Dairy Science, v.81, n.3, p.856$871,1998$.

STAPLES, C.R.; THATCHER, W.W.; MATTOS, R. Fat supplementation strategies for lactating dairy cow diets. In: SINLEITE - SIMPÓSIO INTERNACIONAL DE BOVINOCULTURA DE LEITE, 2., 2001, Lavras. Anais... Lavras: Universidade Federal de Lavras, 2001. p.161-178.

TAMMINGA, S.; LUTEIJN, P.A.; MEIJER, R.G.M. Changes in composition and energy content of liveweight loss in dairy cows with time after parturition. Livestock Production Science, v.52, n.1, p.31-38, 1997.

Van SOEST, P.J.; MASON, V.C. The influence of Maillard reaction upon the nutritive value of fibrous feeds. Animal Feed Science and Technology, v.32, n.1, p.45-53, 1991. 